\title{
Performance Analysis of a Peak-Current Mode Control with Compensation Ramp for a Boost-Flyback Power Converter
}

\author{
Juan-Guillermo Muñoz, Guillermo Gallo, Gustavo Osorio, and Fabiola Angulo \\ Facultad de Ingeniería y Arquitectura, Departamento de Ingeniería Eléctrica, Electrónica y Computación, \\ Percepción y Control Inteligente, Bloque Q, Universidad Nacional de Colombia Sede Manizales, Campus La Nubia, \\ 170003 Manizales, Colombia \\ Correspondence should be addressed to Fabiola Angulo; fangulog@unal.edu.co
}

Received 21 January 2016; Revised 13 March 2016; Accepted 22 March 2016

Academic Editor: Ayman S. Abdel-Khalik

Copyright (C) 2016 Juan-Guillermo Muñoz et al. This is an open access article distributed under the Creative Commons Attribution License, which permits unrestricted use, distribution, and reproduction in any medium, provided the original work is properly cited.

\begin{abstract}
High voltage gain power converters are very important in photovoltaic applications mainly due to the low output voltage of photovoltaic arrays. This kind of power converters includes three or more semiconductor devices and four or more energy storage elements, making the dynamical analysis of the controlled system more difficult. In this paper, the boost-flyback power converter is controlled by peak-current mode with compensation ramp. The closed-loop analysis is performed to guarantee operation conditions such that a period-1 orbit is attained. The converter is considered as a piecewise linear system, and the closed-loop stability is determined by using the monodromy matrix, obtained by the composition of the saltation matrixes with the solutions of the dynamical equations in the linear intervals. The largest eigenvalue of the monodromy matrix gives the stability of the period-1 orbit, and a deep analysis using bifurcation diagrams let us reach a conclusion about the loss of the stability, which is experimentally verified. To avoid overcompensation effects, the minimum value required by the compensation ramp is obtained, and the minimum and maximum values of the load resistance are found too. The system has a good transient response under disturbances in the load and in the input voltage.
\end{abstract}

\section{Introduction}

High gain power converters have attracted great interest thanks to the wide variety of new applications. Photovoltaic panels and fuel cells are application examples, in which high gain power converters play an important role in the development of new architectures aiming to improve the power systems efficiency and energy quality [1]. The classic boost converter is a simple structure but, in practice, only works for voltage gains near to two and needs extreme duty cycles for higher voltage gains [2]. Extreme duty cycles are undesirable, because the MOSFET is closed most of the time and the conduction power losses increase. To avoid extreme duty cycles, a slope compensation may be used. However, as the slope increases, the system exhibits overcompensation [3] and limitations for high gains are present again. To solve this problem, new converters have been designed and tested. Most of these new technologies use more semiconductor elements and more storage energy elements, and, consequently, the nonlinear behavior rises as well as the complexity of the model. As the complexity increases, there are new challenges regarding control strategies and stability analysis.

In this paper, we analyze the boost-flyback converter which was initially proposed in $[2,4,5]$ and then studied in [6]. It is a high gain voltage converter with two capacitors, two coupled inductors, one controlled switch (MOSFET), and two uncontrolled switches (diodes). The main practical advantages of this converter are as follows: no extreme duty cycles are required to obtain high voltage gains and the rectifier reverse recovery problem is alleviated [2]. Starting from this basic structure, new and different configurations have been proposed. A summary list of applications of the coupled inductor in dc-dc converters can be found in [7]. Photovoltaic applications of boost-flyback converters have been studied in [8] and battery charging applications in [9]. In [10], a singlestage single-switch parallel boost-flyback-flyback converter 
with high gain and high efficiency is proposed and analyzed by linearization of its large signal equations. In [11], a coupled inductor is used in the boost-cell of boost-flyback converter to reduce the voltage stress across the output diode and obtain ripple free input current, increasing the complexity of the model. In [12], high voltage gain is obtained by using inputparallel output-series of two windings of coupled inductor; even though the objective is reached, the complexity of the model increases considerably, making it more difficult to analyze the system. In [13], a system based on coupled inductor transfer source energy is designed and analyzed in steady state. To obtain the desired results, four capacitors and four diodes are used. In [14], a small signal modelling for high voltage gain and high efficiency dc-dc converters is developed. This approach does not include nonlinear behavior and the results cannot be confirmed. In [15], a new high step-up dc-dc converter with three capacitors, three inductors, four diodes, and one MOSFET is designed (i.e., six dynamical equations and 32 possible topologies to analyze).

Despite the fact that a lot of work has been devoted to analyze and control systems similar to the boost-flyback converter, there are three main weaknesses associated: (1) all the reported analyses are performed by linear methods starting from a chosen steady-state solution. As the system is highly nonlinear, it is not possible to guarantee the steady state, since eventually the system state may evolve to a different limit solution. (2) The mathematical tools to analyze the dynamical behavior are based on linear systems, for which nonlinear phenomena, such as coexistence of attracting solutions, bifurcating phenomena, quasiperiodicity, and even chaos, cannot be investigated. (3) Most of the proposed systems have six or more energy storage elements and three or more semiconductor devices, increasing the complexity of dynamic equations to be analyzed which is probably the reason why rigorous mathematical analyses are not performed in any paper.

In this paper, we analyze and control the boost-flyback converter using nonlinear methods to guarantee operation in a defined oscillating steady state using bifurcation diagrams. The analysis uses numerical tools for piecewise smooth linear models [16], in order to derive analytic conditions for stability of solutions and to determine a suitable set of parameters. The study focusses on the stability analysis for periodic orbits by means of the spectrum of the fundamental matrix associated with an equivalent discrete map [17]. The analytical procedure implies the use of a saltation matrix $[17,18]$, in order to infer some implicit time derivatives related to the switching times. The system is controlled by a PI (Proportional Integral) peak-current controller with slope compensation. A peakcurrent controller with slope compensation has been studied with basic topologies [19-21], where the design parameters are determined in order to avoid overcompensations [3]. The limit value of the slope compensation as well as the range of the load resistances is computed analytically and confirmed by bifurcation diagrams obtained numerically. As far as we know, neither mathematical tools nor PI peakcurrent control with slope compensation has been used to analyze and control the boost-flyback converter. Finally, to complete the work, an experiment has been designed and experimental data are consistent with numerical results.
The paper is organized as follows. In Section 2, the mathematical model in open-loop and the PI peak-current controller with compensation ramp are introduced. In Section 3, the stability analysis and bifurcation diagrams are computed. The stability is performed based on the study of the monodromy matrix, using saltation matrixes. Bifurcation diagrams are computed by numerical methods, confirming and widening the results obtained by the monodromy matrix. With these results, limits on load resistance, input voltage, reference voltage, and compensation slope are obtained. In Section 4, the dynamical behavior is performed, when different disturbances are considered. In Section 5, experimental results showing the loss of the stability of the period-1 orbit and the transition to chaos are displayed. Conclusions are presented in the last section.

\section{The Controlled Boost-Flyback Converter}

The peak-current control for a boost-flyback converter is schematized in Figure 1. The aim of this converter is to obtain high voltage gains without extreme duty cycle values. The duty cycle, noted as $d \in\left[\begin{array}{ll}0 & 1\end{array}\right]$, is the ratio between the time that the MOSFET is closed $t_{\text {on(MOSFET) }}$ and the period $T$ of an external clock.

The controlled boost-flyback converter is composed by two magnetically coupled inductors $\left(L_{p}\right.$ and $\left.L_{s}\right)$, one MOSFET $(S)$, two diodes $\left(D_{1}\right.$ and $\left.D_{2}\right)$, two capacitors $\left(C_{1}\right.$ and $\left.C_{2}\right)$, the load resistance $(R)$, and two control loops, one external (for the voltage) and one internal (for the current). The external loop includes a PI control action for the error $e:=$ $V_{\text {ref }}-V_{\text {out }}$ and a compensation ramp with slope $A_{r} / T$. This loop generates the reference value for the internal current control loop. Finally, a RS flip-flop with external clock is used. The purpose is to obtain and keep a desired regulated voltage value $\left(V_{\text {ref }}\right)$ across the terminals of the load $R$, even in the case when some parameters change their values. The output voltage is taken from the voltages across the capacitors $C_{1}$ and $C_{2}$; that is, $V_{\text {out }}=V_{C 1}+V_{C 2}$. This configuration has the features from the boost and the flyback converters in a single structure, obtaining high voltage gains without extreme duty cycles $[4,5]$. Its drawback is the complexity mainly due to two reasons. The first one is the increasing number of topological configurations, as a result of the diodes and the MOSFET. There are, in fact, eight possible topologies but only six of them are physically reachable. The second reason is that the diodes are not controllable; that is, they commute according to the voltage across their terminals or the current passing through them, and no external signal can be applied to change the diode position. This restriction can make it difficult to control the system. Despite these facts, in this paper, the equations describing the dynamical system are found and a peak-current controller is designed and analyzed to guarantee (1) stability of the period-1 orbit in a determined range of the parameter values, (2) fast transient response, and (3) voltage gains near to five without extreme duty cycles and with low output error; that is, $e \approx 0$.

2.1. Modelling. To model the PI peak-current controller for a boost-flyback converter, we consider the following 


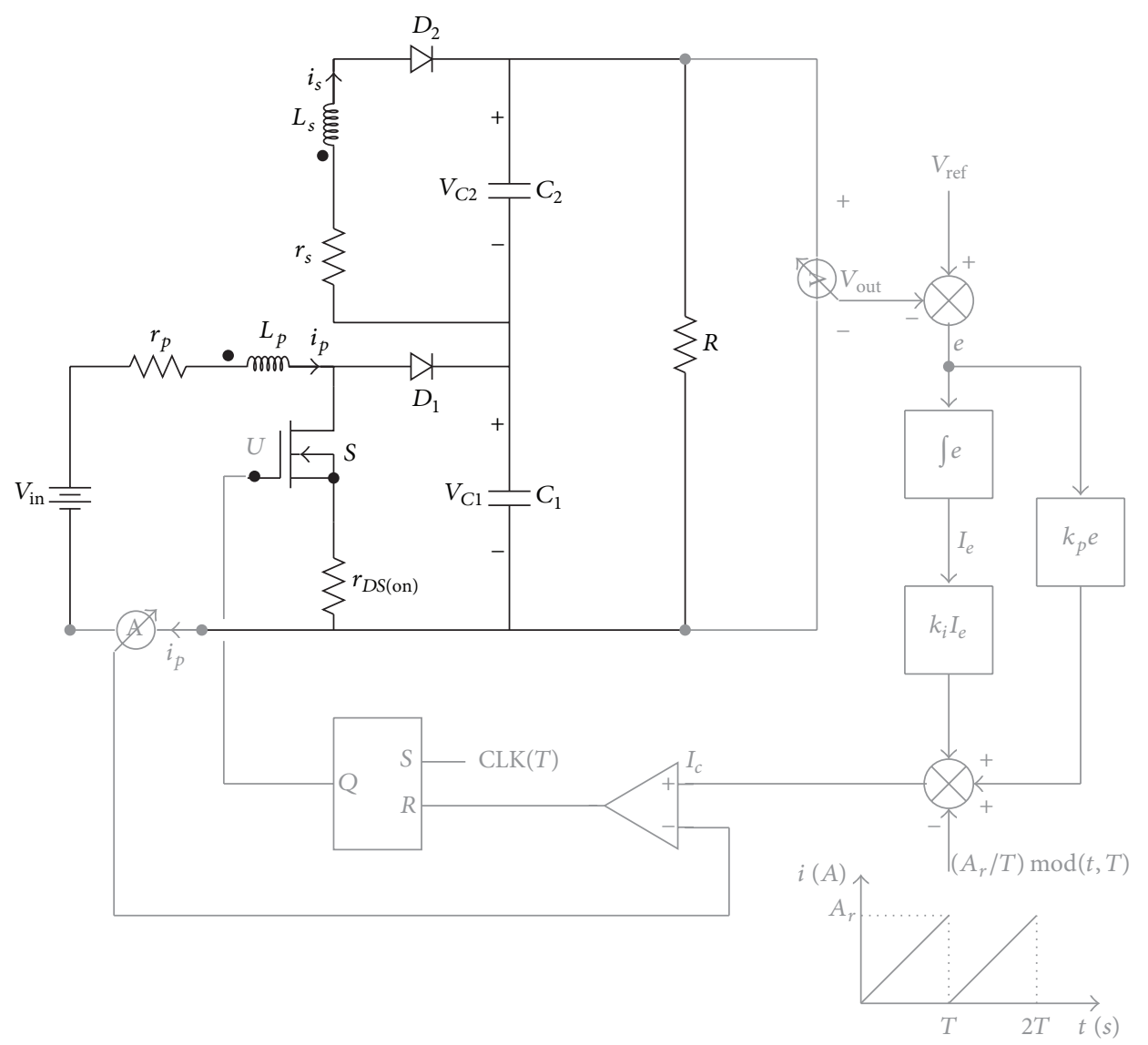

FIGURE 1: Schematic diagram of the peak-current control with compensation ramp for a boost-flyback converter.

assumptions: (1) the MOSFET and diodes work as ideal switches; that is, they have only on and off positions and the change is instantaneous, (2) the diodes do not have internal resistances, (3) capacitors are ideal, and (4) the internal resistances are constant when they are considered. The equations of the system are given in

$$
\begin{aligned}
V_{p} & =L_{p} \frac{d i_{p}}{d t}+M \frac{d i_{s}}{d t}+\left(r_{p}+r_{\mathrm{DS}(\mathrm{on})}\right) i_{p}, \\
V_{s} & =L_{s} \frac{d i_{s}}{d t}+M \frac{d i_{p}}{d t}+r_{s} i_{s}, \\
i_{s} & =C_{2} \frac{d V_{C 2}}{d t}+\frac{V_{C 1}+V_{C 2}}{R}, \\
i_{p} & =C_{1} \frac{d V_{C 1}}{d t}+\frac{V_{C 1}+V_{C 2}}{R}, \\
\frac{d I_{e}}{d t} & =V_{\text {ref }}-\left(V_{C 1}+V_{C 2}\right),
\end{aligned}
$$

where $i_{p}$ and $i_{s}$ are the primary and secondary inductor currents, respectively; $M$ is the magnetizing inductance; $r_{\mathrm{DS}(\mathrm{on})}$ is the MOSFET internal resistance and is only considered when the MOSFET is on; $r_{p}$ and $r_{s}$ are the internal resistances of the primary and secondary inductors; $V_{C 1}$ and $V_{C 2}$ are the voltages across the capacitors $C_{1}$ and $C_{2} ; I_{e}$ is the integral of the output error $e ; V_{p}$ and $V_{s}$ are the voltages across the primary and secondary inductors, and they must be replaced such that a set of solvable differential equations can be derived. These voltages depend on the MOSFET and diode positions leading to six possible states from $E_{1}$ to $E_{6}$ which are listed in Table 1 . Taking the state variables $X:=\left[\begin{array}{lllll}i_{p} & i_{s} & V_{C 1} & V_{C 2} & I_{e}\end{array}\right]^{T}$ and replacing $V_{p}$ and $V_{s}$ by the corresponding expressions, the system can be expressed in a compact form as

$$
\dot{X}(t)=A_{i} X(t)+B_{i} V_{\text {in }} .
$$

(i) State $1\left(E_{1}\right)$ is

$$
A_{1}=\left[\begin{array}{ccccc}
0 & 0 & 0 & 0 & 0 \\
0 & 0 & 0 & 0 & 0 \\
0 & 0 & -\frac{1}{R C_{1}} & -\frac{1}{R C_{1}} & 0 \\
0 & 0 & -\frac{1}{R C_{2}} & -\frac{1}{R C_{2}} & 0 \\
0 & 0 & -1 & -1 & 0
\end{array}\right] \text {, }
$$


TABLE 1: States of the boost-flyback converter.

\begin{tabular}{llll}
\hline State & $S$ & $D 2$ & $D 1$ \\
\hline$E_{1}$ & Off & Off & Off \\
$E_{2}$ & Off & Off & On \\
$E_{3}$ & Off & On & Off \\
$E_{4}$ & Off & On & On \\
$E_{5}$ & On & Off & Off \\
$E_{6}$ & On & On & Off \\
\hline
\end{tabular}

$$
B_{1}=\left[\begin{array}{c}
0 \\
0 \\
0 \\
0 \\
\frac{V_{\text {ref }}}{V_{\text {in }}}
\end{array}\right]
$$

(3)

(ii) State $2\left(E_{2}\right)$ is

$$
\begin{aligned}
A_{2} & =\left[\begin{array}{ccccc}
-\frac{r_{p}}{L_{p}} & 0 & -\frac{1}{L_{p}} & 0 & 0 \\
0 & 0 & 0 & 0 & 0 \\
\frac{1}{C_{1}} & 0 & -\frac{1}{R C_{1}} & -\frac{1}{R C_{1}} & 0 \\
0 & 0 & -\frac{1}{R C_{2}} & -\frac{1}{R C_{2}} & 0 \\
0 & 0 & -1 & -1 & 0
\end{array}\right], \\
B_{2} & =\left[\begin{array}{c}
\frac{1}{L_{p}} \\
0 \\
0 \\
0 \\
\frac{V_{\text {ref }}}{V_{\text {in }}}
\end{array}\right] .
\end{aligned}
$$

(4)

(iii) State $3\left(E_{3}\right)$ is

$$
A_{3}=\left[\begin{array}{ccccc}
0 & 0 & 0 & 0 & 0 \\
0 & -\frac{r_{s}}{L_{s}} & 0 & -\frac{1}{L_{s}} & 0 \\
0 & 0 & -\frac{1}{R C_{1}} & -\frac{1}{R C_{1}} & 0 \\
0 & \frac{1}{C_{2}} & -\frac{1}{R C_{2}} & -\frac{1}{R C_{2}} & 0 \\
0 & 0 & -1 & -1 & 0
\end{array}\right],
$$

$$
B_{3}=\left[\begin{array}{c}
0 \\
0 \\
0 \\
0 \\
\frac{V_{\text {ref }}}{V_{\text {in }}}
\end{array}\right]
$$

(iv) State $4\left(E_{4}\right)$ is

$$
A_{4}=\left[\begin{array}{ccccc}
-\frac{L_{s} r_{p}}{m} & \frac{M r_{s}}{m} & -\frac{L_{s}}{m} & \frac{M}{m} & 0 \\
\frac{M r_{p}}{m} & -\frac{L_{p} r_{s}}{m} & \frac{M}{m} & -\frac{L_{p}}{m} & 0 \\
\frac{1}{C_{1}} & 0 & -\frac{1}{R C_{1}} & -\frac{1}{R C_{1}} & 0 \\
0 & \frac{1}{C_{2}} & -\frac{1}{R C_{2}} & -\frac{1}{R C_{2}} & 0 \\
0 & 0 & -1 & -1 & 0
\end{array}\right],
$$

$$
B_{4}=\left[\begin{array}{c}
\frac{L_{s}}{m} \\
-\frac{M}{m} \\
0 \\
0 \\
\frac{V_{\text {ref }}}{V_{\text {in }}}
\end{array}\right]
$$

(v) State $5\left(E_{5}\right)$ is

$$
A_{5}=\left[\begin{array}{ccccc}
-\frac{\left(r_{p}+r_{\mathrm{DS}(\mathrm{on})}\right)}{L_{p}} & 0 & 0 & 0 & 0 \\
0 & 0 & 0 & 0 & 0 \\
0 & 0 & -\frac{1}{R C_{1}} & -\frac{1}{R C_{1}} & 0 \\
0 & 0 & -\frac{1}{R C_{2}} & -\frac{1}{R C_{2}} & 0 \\
0 & 0 & -1 & -1 & 0
\end{array}\right],
$$

$$
B_{5}=\left[\begin{array}{c}
\frac{1}{L_{p}} \\
0 \\
0 \\
0 \\
\frac{V_{\text {ref }}}{V_{\text {in }}}
\end{array}\right]
$$


(vi) State $6\left(E_{6}\right)$ is

$A_{6}$

$$
=\left[\begin{array}{ccccc}
-\frac{L_{s}\left(r_{p}+r_{\mathrm{DS}(\mathrm{on})}\right)}{m} & \frac{M r_{s}}{m} & 0 & \frac{M}{m} & 0 \\
\frac{M\left(r_{p}+r_{\mathrm{DS}(\mathrm{on})}\right)}{m} & -\frac{L_{p} r_{s}}{m} & 0 & -\frac{L_{p}}{m} & 0 \\
0 & 0 & -\frac{1}{R C_{1}} & -\frac{1}{R C_{1}} & 0 \\
0 & \frac{1}{C_{2}} & -\frac{1}{R C_{2}} & -\frac{1}{R C_{2}} & 0 \\
0 & 0 & -1 & -1 & 0
\end{array}\right] \text {, }
$$

$$
B_{6}=\left[\begin{array}{c}
\frac{L_{s}}{m} \\
-\frac{M}{m} \\
0 \\
0 \\
\frac{V_{\text {ref }}}{V_{\text {in }}}
\end{array}\right],
$$

where $i \in\{1,2,3,4,5,6\}$ corresponds to the state of the switches in the system. $V_{\text {in }}$ is the input voltage, $A_{i}$ and $B_{i}$ are associated with the state $E_{i}$, and $m=L_{p} L_{s}-M^{2}$. As the state of the converter changes among $E_{1} \cdots E_{6}$ depending on the position of semiconductor devices, the system can be modeled as a piecewise linear system [22]. A complete description to obtain the state equations is analyzed in [6]. The states $E_{1}, E_{2}, E_{3}$, and $E_{4}$ can be present when the MOSFET is off, and states $E_{5}$ and $E_{6}$ can be present if the MOSFET is on. The state transition diagram is shown in Figure 2 and the conditions for the transitions are $c_{1}: I_{c}-i_{p} \leq$ $0 ; c_{2}: \bmod (t, T)=0, \wedge, I_{c}-i_{p}>0 ; c_{3}: V_{C 1}+V_{p}-V_{\text {in }} \leq 0$; $c_{4}: i_{p} \leq 0 ; c_{5}: i_{s} \leq 0 ; c_{6}: V_{C 2}+V_{s} \leq 0$; and $c_{7}: I_{c}-i_{p} \leq$ $0, \wedge, V_{C 2}+V_{s} \leq 0, \wedge, d I_{p} / d t \leq 0$.

2.2. Peak-Current Controller. The peak-current mode control has been successfully applied to power converters $[19,20,23-$ 25 ], and it works as follows. The error of the system, $e$, is scaled and integrated through a PI controller to generate the control signal $K_{p}\left(V_{\text {ref }}-\left(x_{3}(t)+x_{4}(t)\right)\right)+K_{i} x_{5}(t)$. The compensation ramp is subtracted from this value to obtain the peak-current reference $I_{c}$ given by

$$
\begin{aligned}
I_{c}= & K_{p}\left(V_{\mathrm{ref}}-\left(x_{3}(t)+x_{4}(t)\right)\right)+K_{i} x_{5}(t) \\
& -\frac{A_{r}}{T} \bmod (t, T)
\end{aligned}
$$

where $A_{r}>0$. The $I_{c}$ signal is compared with the primary inductor current and the result of this comparison enters to reset flip-flop pin. The set flip-flop pin is connected to an external clock with period $T$, switching on the MOSFET at the beginning of each cycle. When the primary inductor current is lower than $I_{c}$, the flip-flop output is logic 1 and the MOSFET is on $(U=1)$. If the primary inductor current is equal to or greater than $I_{c}$, then the flip-flop is reset and

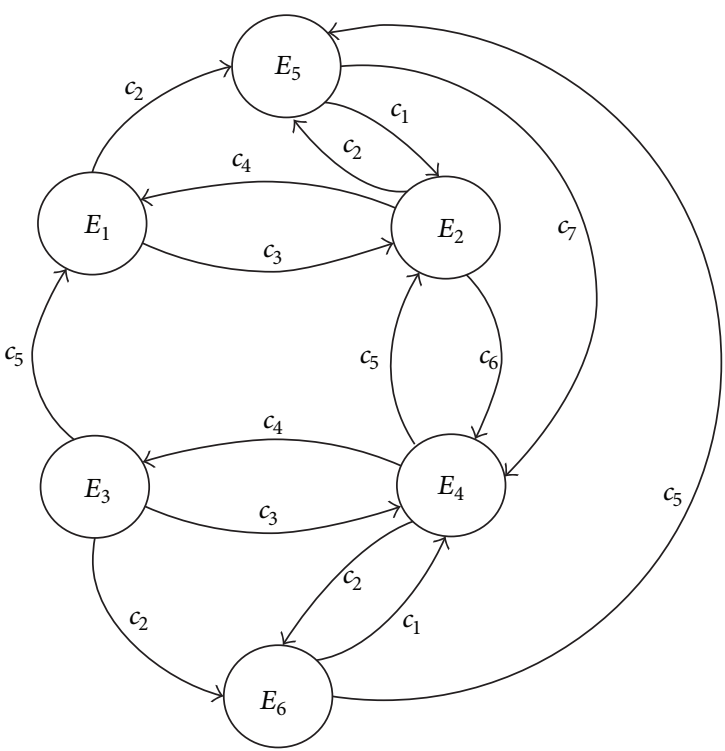

FIGURE 2: State transition diagram.

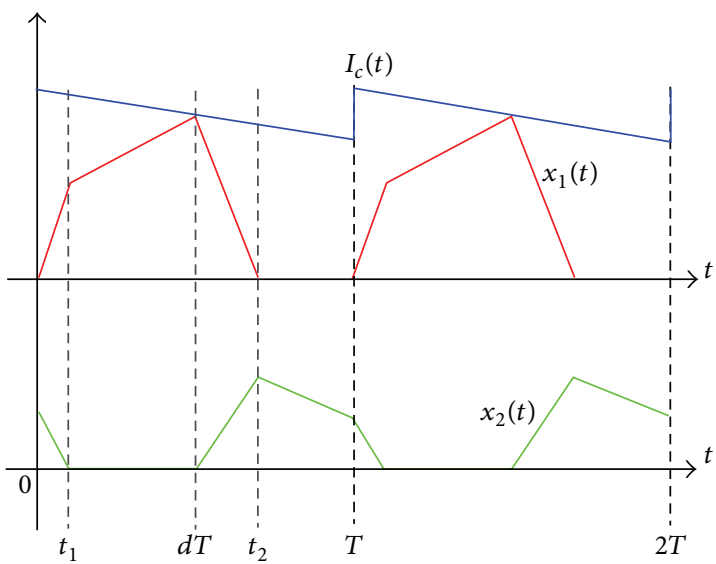

FIGURE 3: Behavior of primary (top) and secondary inductor (bottom) currents in steady state.

the MOSFET changes to off $(U=0)$ and it remains in this position until the beginning of next cycle, when it changes to on again. The duty cycle is defined as $d=t_{\text {on(MOSFET) }} / T$ and $d \in[0,1]$.

\section{Stability and Bifurcation Diagrams Analysis}

Figure 3 presents the behavior of the primary and secondary inductor currents operating in a period-1 orbit. For the chosen parameters (see Table 2 ), the numerical analysis determined that the states involved in this periodic solution are $E_{6}$, $E_{5}, E_{4}$, and $E_{3}$ (see Table 1). The MOSFET is closed when the system operates in $E_{6}$ and $E_{5}$, and it is open in states $E_{4}$ and $E_{3}$. The solution of the system in one period $(T)$ is given by

$$
X((k+1) T)=\phi_{6}\left(\phi_{5}\left(\phi_{4}\left(\phi_{3}(X(k T))\right)\right)\right),
$$

where $\phi_{i}(X(\cdot))$ is the solution of the linear part in the corresponding interval of time $\Delta t_{i}$, with its corresponding 
TABLE 2: Parameter values.

\begin{tabular}{lc}
\hline \multicolumn{3}{c}{ Parameters } \\
\hline$L_{p}$ & $183 \mu \mathrm{H}$ \\
$L_{s}$ & $724 \mu \mathrm{H}$ \\
$M$ & $362.5 \mu \mathrm{H}$ \\
$r_{p}$ & $0.078 \Omega$ \\
$r_{s}$ & $0.312 \Omega$ \\
$r_{\mathrm{DS}(\mathrm{on})}$ & $0.044 \Omega$ \\
$C_{1}$ & $220 \mu \mathrm{F}$ \\
$C_{2}$ & $220 \mu \mathrm{F}$ \\
$R$ & $100 \Omega$ \\
$K_{p}$ & $2 \mathrm{~A} / \mathrm{V}$ \\
$K_{i}$ & 350 \\
$A_{r}$ & $2.8 \mathrm{~A}$ \\
$V_{\text {ref }}$ & $100 \mathrm{~V}$ \\
$T$ & $1 / 12000 \mathrm{~s} \approx 83.3 \mu \mathrm{s}$ \\
\hline
\end{tabular}

initial condition. It can be computed as $\phi_{i}(X(\cdot))=e^{A_{i} \Delta t_{i}} X(\cdot)$ $+\int_{0}^{\Delta t_{i}} e^{A_{i}\left(\Delta t_{i}-\tau\right)} B_{i} V_{\text {in }} d \tau$. Equation (10) can be expressed in a simplified way as

$$
X((k+1) T)=\Phi(X(k T)) .
$$

If $\Phi(X(k T))$ is such that $X((k+1) T)=X(k T)$, we have the solution of the period-1 orbit. The procedure to determine the stability of period-1 orbit in smooth systems is simpler than in switched systems, because in the last case it is necessary to consider the discontinuity in the vector field. Then, in this kind of systems, the monodromy matrix $(M)$ is computed using the solutions of the system in the linear part and introducing the correction provided by the saltation matrixes at the switching instants [26]. This matrix allows finding the relation between the state variables at the end of one period with respect to the ones starting very close to the period-1 solution, such that

$$
X_{p}((k+1) T)=M X_{p}(k T)
$$

where the subscript $p$ refers to the perturbed state at the beginning and the end of one cycle. As there are four states $E_{i}$, then there are three changes in the position of MOSFET/diodes. The switching times are noted as $t_{\Sigma_{1}}=t_{1}$, $t_{\Sigma_{2}}=d T$, and $t_{\Sigma_{3}}=t_{2}$ (see Figure 3 ), and $M$ is computed as

$$
\begin{aligned}
M= & \phi\left(A_{3}, B_{3}, t=t_{2} \cdots T\right) \cdot S_{3} \\
& \cdot \phi\left(A_{4}, B_{4}, t=d T \cdots t_{2}\right) \cdot S_{2} \\
& \cdot \phi\left(A_{5}, B_{5}, t=t_{1} \cdots d T\right) \cdot S_{1} \\
& \cdot \phi\left(A_{6}, t=0 \cdots t_{1}\right),
\end{aligned}
$$

where $S_{i}$ are the saltation matrixes associated with each switching instant. In general, the expression to evaluate $S$ is given by

$$
S=I+\frac{\left(f_{+}\left(X\left(t_{\Sigma}\right), t_{\Sigma}\right)-f_{-}\left(X\left(t_{\Sigma}\right), t_{\Sigma}\right)\right) n^{T}}{n^{T} f_{-}\left(X\left(t_{\Sigma}\right), t_{\Sigma}\right)+\left.(\partial h(X(t), t) / \partial t)\right|_{t=t_{\Sigma}}}
$$

where $t_{\Sigma}$ is the switching instant; $I$ is the identity matrix with proper dimensions; $f_{-}\left(X\left(t_{\Sigma}\right), t_{\Sigma}\right)$ and $f_{+}\left(X\left(t_{\Sigma}\right), t_{\Sigma}\right)$ are the vector fields before and after the switching time, respectively; $h(X(t), t)$ is the corresponding switching surface; and $n$ is the normal vector to the switching surface that is computed as

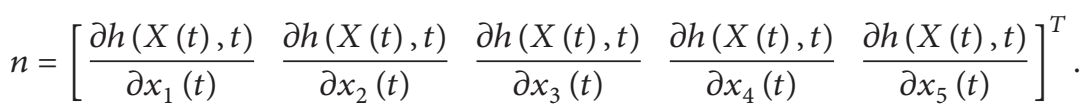

The three saltation matrixes are computed using the following equations. The first commutation arises when the secondary inductor current $x_{2}(t)$ goes down to zero. The switching instant is called $t=t_{1}$ (see Figure 3 ). The switching surface $h_{1}(X(t), t), \partial h_{1}(X(t), t) / \partial t$, and the normal vector are given by

$$
\begin{aligned}
h_{1}(X(t), t) & =x_{2}(t), \\
\left.\frac{\partial h_{1}(X(t), t)}{\partial t}\right|_{t=t_{1}} & =0 \\
n_{1} & =\left[\begin{array}{lllll}
0 & 1 & 0 & 0 & 0
\end{array}\right]^{T} .
\end{aligned}
$$

The vector fields before and after switching instants evaluated at $t_{\Sigma_{1}}$ are

$$
\begin{aligned}
& f_{-}\left(X\left(t_{1}\right), t_{1}\right)=A_{6} X\left(t_{1}\right)+B_{6} V_{\text {in }} \\
& f_{+}\left(X\left(t_{1}\right), t_{1}\right)=A_{5} X\left(t_{1}\right)+B_{5} V_{\text {in }} .
\end{aligned}
$$

The second commutation occurs when the primary inductor current $x_{1}(t)$ reaches the current reference given by the controller. This switching instant is called $t_{\Sigma_{2}}=d T$ and defines the duty cycle. The equations to define the switching surface $\left(h_{2}(X(t), t)\right), \partial h_{2}(X(t), t) / \partial t$, and the normal vector are given by

$$
\begin{aligned}
h_{2}(X(t), t)= & K_{p}\left(V_{\text {ref }}-\left(x_{3}(t)+x_{4}(t)\right)\right) \\
& +K_{i} x_{5}(t)-\frac{A_{r}}{T} \bmod \left(\frac{t}{T}\right) \\
& -x_{1}(t), \\
\frac{\left.\partial h_{2}(X(t), t)\right|_{t=d T}=}{\partial t} & -\frac{A_{r}}{T}, \\
n_{2}= & {\left[\begin{array}{lllll}
-1 & 0 & -K_{p}-K_{p} & K_{i}
\end{array}\right]^{T} . }
\end{aligned}
$$




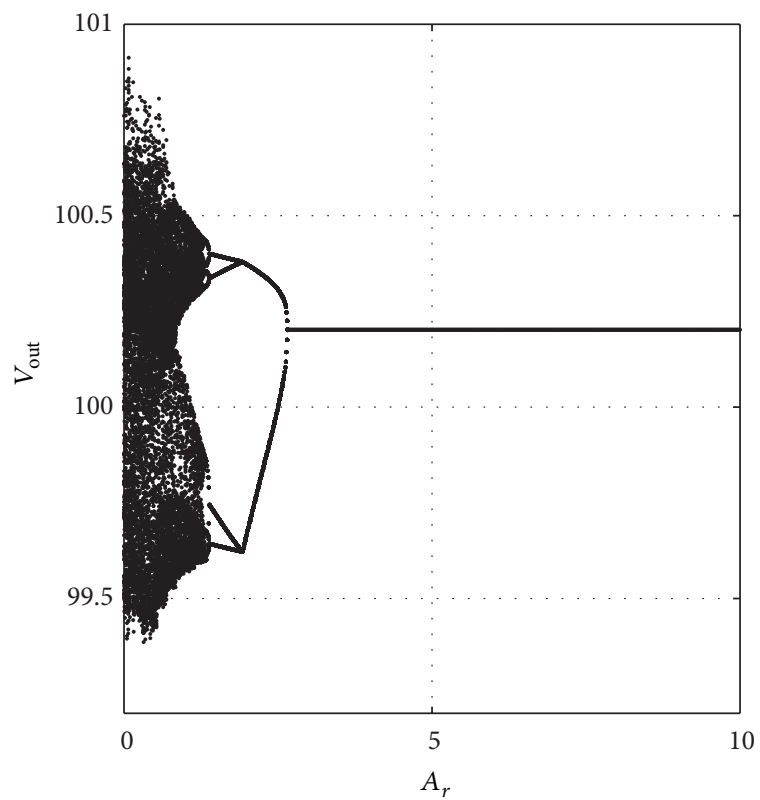

(a) Bifurcation diagram varying $A_{r}$

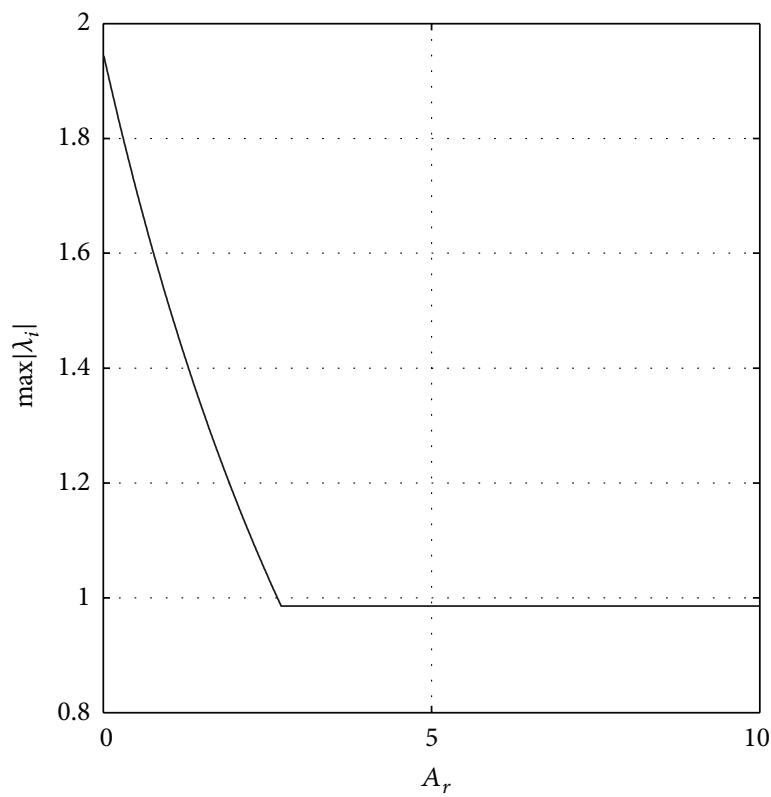

(b) Evolution of the LAVE

FIGURE 4: Steady state and stability of period-1 orbit as $A_{r}$ varies in $[0,10] \mathrm{A}$.

The vector fields before and after switching instants are

$$
\begin{aligned}
& f_{-}(X(d T), d T)=A_{5} X(d T)+B_{5} V_{\text {in }}, \\
& f_{+}(X(d T), d T)=A_{4} X(d T)+B_{4} V_{\text {in }} .
\end{aligned}
$$

The last commutation arises when the primary inductor current $x_{1}(t)$ goes down to zero. This time is noted as $t_{\Sigma_{3}}=$ $t_{2}$. The equations and terms associated with this switching instant are

$$
\begin{aligned}
h_{3}(X(t), t) & =x_{1}(t), \\
\left.\frac{\partial h_{3}(X(t), t)}{\partial t}\right|_{t=t_{2}} & =0, \\
n_{3} & =\left[\begin{array}{lllll}
1 & 0 & 0 & 0 & 0
\end{array}\right]^{T}, \\
f_{-}\left(X\left(t_{2}\right), t_{2}\right) & =A_{4} X\left(t_{2}\right)+B_{4} V_{\text {in }}, \\
f_{+}\left(X\left(t_{2}\right), t_{2}\right) & =A_{3} X\left(t_{2}\right)+B_{3} V_{\text {in }} .
\end{aligned}
$$

The general procedure to assess the stability of the period1 orbit in this kind of switched systems can be summarized as follows [21]:

(1) Find the value of the state vector $X$ at the beginning of the period-1 orbit (noted as $X^{*}$ ) together with the switching times $t_{1}, d T$, and $t_{2}$, solving the following equations:

$$
\begin{aligned}
X^{*} & =\Phi\left(X^{*}\right) \quad \text { equation }(11) \\
0 & =x_{2}\left(t_{1}\right) \\
0 & =I_{c}(d T)-x_{1}(d T) \\
0 & =x_{1}\left(t_{2}\right) .
\end{aligned}
$$

(2) Once $X^{*}, t_{1}, d T$, and $t_{2}$ are found, compute the saltation matrix $S_{i}$ (from (14) and (16)-(20)) and the monodromy matrix (from (13)).

(3) Next, compute $X_{p}((k+1) T)=M X_{p}(k T)$, where the subscript $p$ refers to the perturbed orbit.

(4) Compute all eigenvalues $\left(\lambda_{i}\right)$ of $M$.

(5) If all eigenvalues are within the unit circle, then the period-1 orbit is stable.

Using the procedure described before and data from Table 2, we proceed to determine the stability of the period1 orbit for the peak-current controlled boost-flyback converter. Figure 4(a) shows the bifurcation diagram when the amplitude of compensation $\operatorname{ramp} A_{r} \in[0,10]$ A changes and $V_{\text {in }}=18 \mathrm{~V}$, and Figure $4(\mathrm{~b})$ presents the behavior of the Largest Absolute Value of its Eigenvalues (LAVE). The bifurcation analysis lets us define the minimum value of the compensation ramp such that the system is stable. As the amplitude increases, the slope increases too, and the system is more stable (see Figure 4(b)), but overcompensation can be present. Close to $A_{r}=2.65 \mathrm{~A}$, the stability of the period1 orbit changes and makes the periodic orbit unstable. The stability is lost through period-doubling bifurcation [27].

In a similar way, the stability of period-1 orbit is analyzed when the input voltage changes in the range $V_{\text {in }} \in[10,18] \mathrm{V}$ and $A_{r}=2.8 \mathrm{~A}$. As in the previous case, the stability is lost by a period-doubling bifurcation, when $V_{\text {in }} \approx 17.3 \mathrm{~V}$. This result is presented in Figure 5(a) and the variation of the LAVE is presented in Figure 5(b). Figures 6(a) and 6(b) show the steady state of the output voltage and the evolution of the LAVE, when the load $R \in[50,300] \Omega, V_{\text {in }}=18 \mathrm{~V}$, and $A_{r}=2.8 \mathrm{~A}$. The system experiences the same bifurcation close to $74.5 \Omega$. 


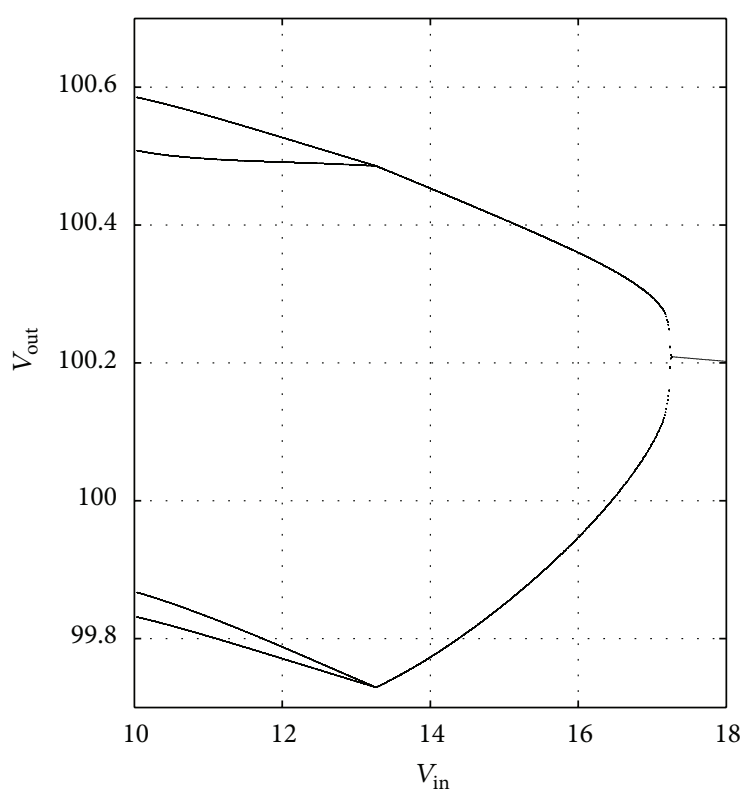

(a) Bifurcation diagram varying $V_{\text {in }}$

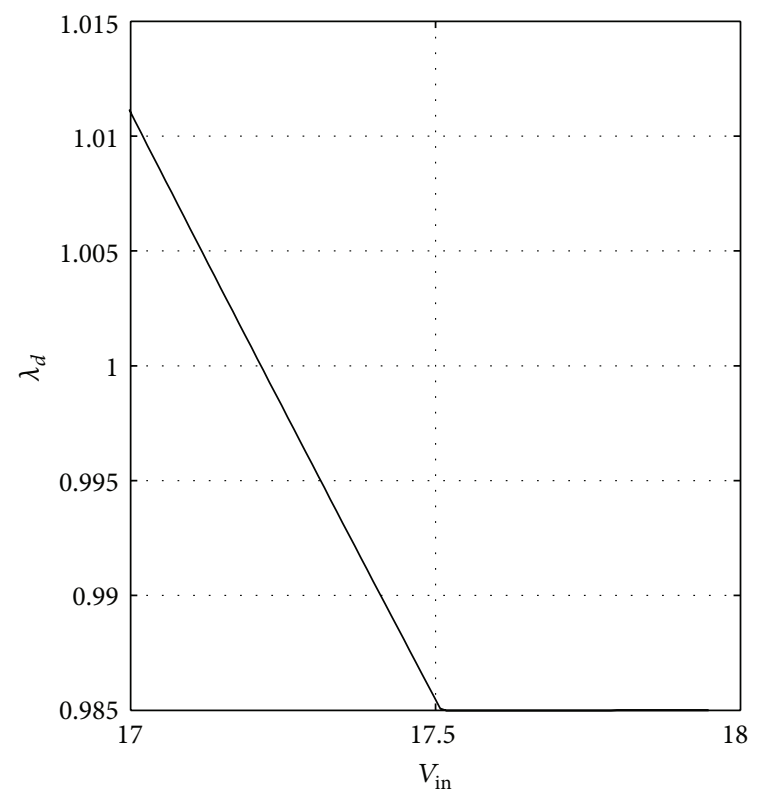

(b) Evolution of the LAVE

FIGURE 5: Steady state and stability of period-1 orbit as $V_{\text {in }}$ varies in $[10,18] \mathrm{V}$.

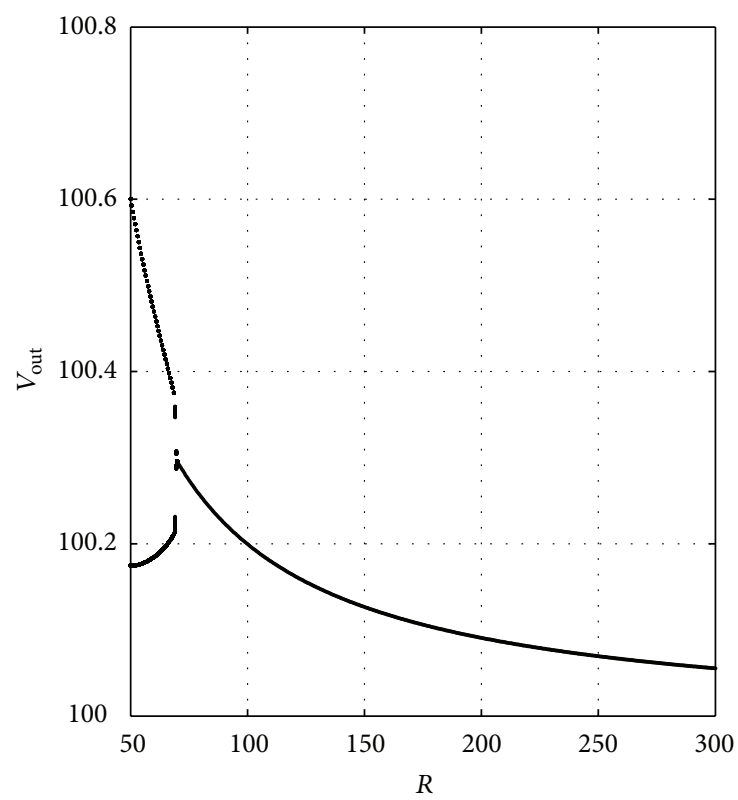

(a) Bifurcation diagram varying $R$

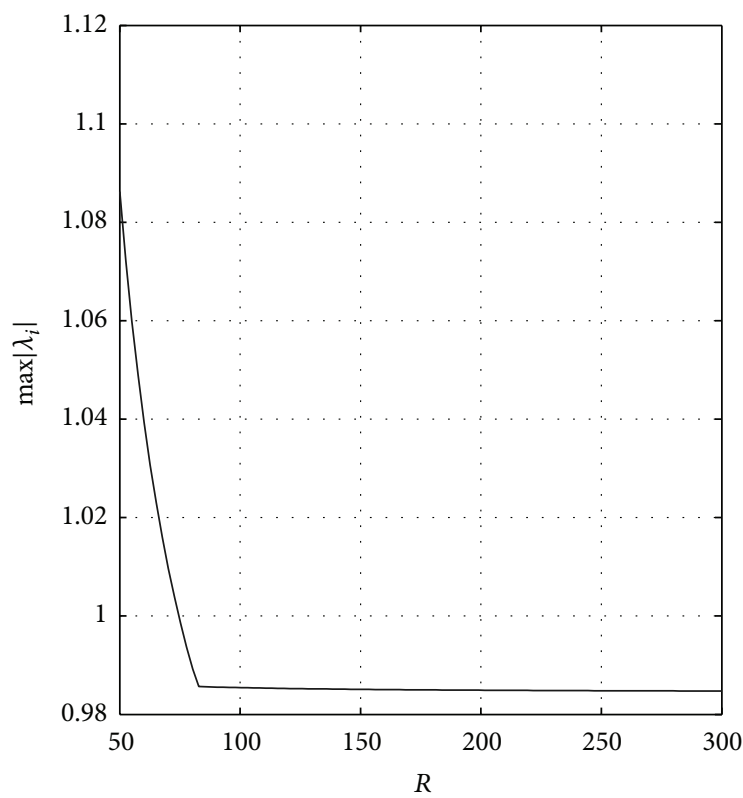

(b) Evolution of the LAVE

Figure 6: Steady state and stability of period-1 orbit as $R$ varies in $[50,300]$ V.

According to the previous results, it is necessary to determine the range of the parameter values such that the orbit is stable. To complete the analysis, the period-1 orbit is analyzed, as two parameters vary. Figures 7(a) and 7(b) show the behavior of the LAVE fixing $A_{r}=2.8 \mathrm{~A}$ and varying $V_{\text {in }} \in[18,25] \mathrm{V}$ and $R \in[80,200] \Omega$, in the first case, and $V_{\text {in }} \in[18,25] \mathrm{V}$ and $V_{\text {ref }} \in[90,120] \mathrm{V}$, in the second one. The stability of the period-1 orbit is guaranteed for $R \in[80$, $200] \Omega, V_{\text {in }} \in[18,25] \mathrm{V}$, and $V_{\text {ref }} \in[90,100] \mathrm{V}$. In other ranges of the parameter values, the system evolves to another period-1 orbit, to a high-periodic orbit, or to a chaotic attractor.

\section{Dynamic Behavior of the Controlled Boost-Flyback Converter}

According to the results, in this section, we test and compare the performance of the controlled system with $A_{r}=2.8 \mathrm{~A}$ 


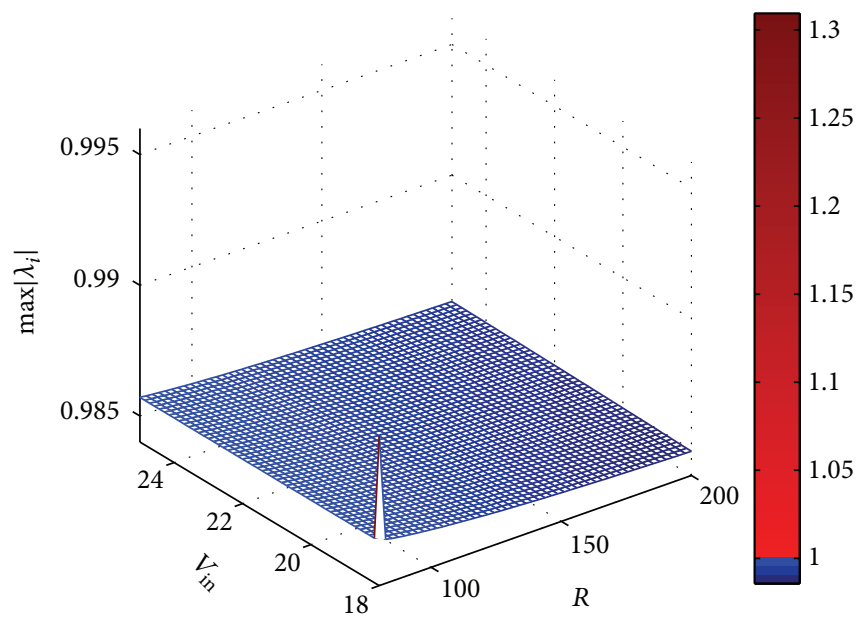

(a) Evolution of the LAVE varying $V_{\text {in }}$ and $R$

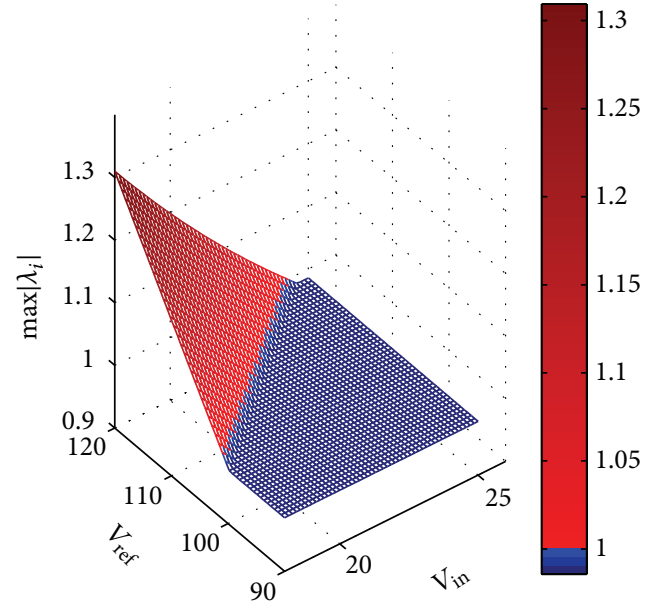

(b) Evolution of the LAVE varying $V_{\text {ref }}$ and $V_{\text {in }}$

FIgURE 7: Period-1 orbit stability.

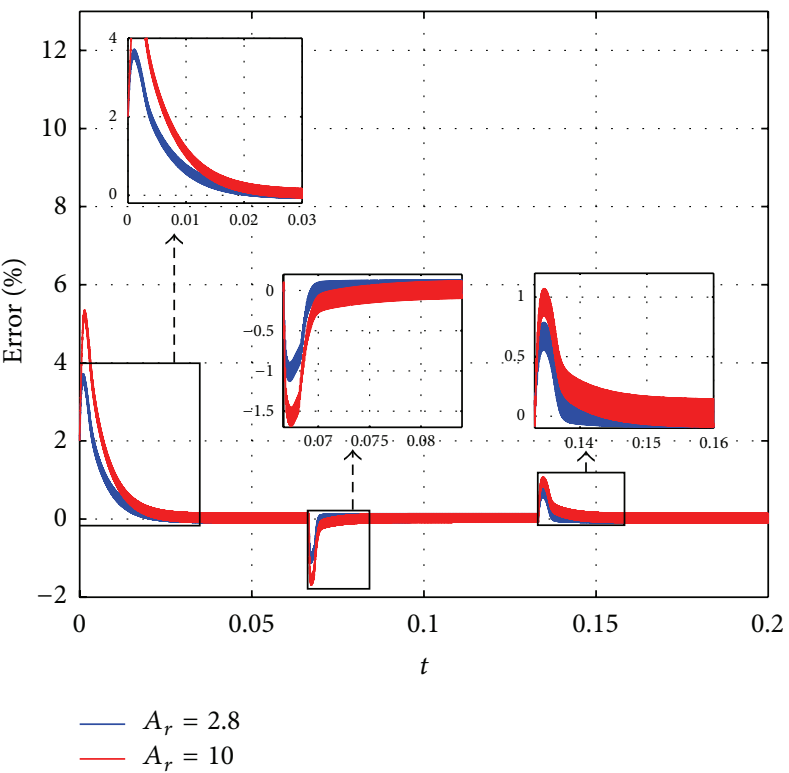

(a) Output voltage error when $V_{\text {in }}$ is perturbed

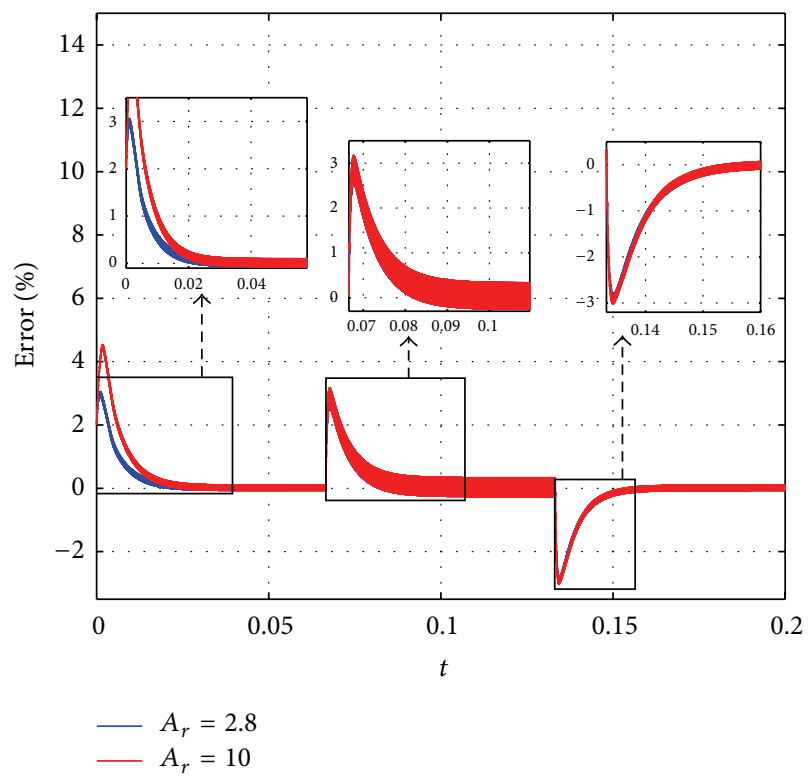

(b) Output voltage error when $R$ is perturbed

FIGURE 8: Error response for different values of $A_{r}$.

and $A_{r}=10 \mathrm{~A}$, when sudden perturbations in the load and in the input voltage are considered. In Figure 8(a), the percentage of the output voltage error is shown when disturbances occur in the input voltage (i.e., $V_{\text {in }} \in[18,25] \mathrm{V}$ ). At $t=$ $0 \mathrm{~s}$, the system is initialized with $X(0)=\left[\begin{array}{lllll}0 & 0 & 49 & 49 & 0\end{array}\right]^{T}$, $V_{\text {in }}=18 \mathrm{~V}$, and $R=200 \Omega$; at $t=66.7 \mathrm{~ms}$, the input voltage changes to $25 \mathrm{~V}$ and then finally turns to $18 \mathrm{~V}$ again at $t=$ $133.2 \mathrm{~ms}$. Figure 8 (b) shows the percentage of output voltage error, when the load is changed. In $t=0 \mathrm{~s}$, the system is initialized with the previous initial conditions, $V_{\text {in }}=18 \mathrm{~V}$ and $R=300 \Omega$; at $t=66.7 \mathrm{~ms}$, the load changes to $80 \Omega$ and then finally changes to $300 \Omega$ at $t=133.2 \mathrm{~ms}$.

The main characteristics of the transient and steady states are presented in Table 3 . The system with lower slope $\left(A_{r}=\right.$
$2.8 \mathrm{~A})$ recovers faster than the system with $A_{r}=10 \mathrm{~A}$. This is because high values of the compensation ramp make it slow. The steady state errors are equal for both values of the compensation ramp. Other performance indexes such as overshoot, maximum current, and integral of the square error have no significant differences.

\section{Experimental Results}

In order to validate the numerical results including some types of behavior of the dynamical system, an experimental set-up was implemented (see Figure 9) and tested. In Table 4, the references of the integrated circuits as well as other parameter values are presented. $R_{\text {span }}$ varies from $4.5 \Omega$ 


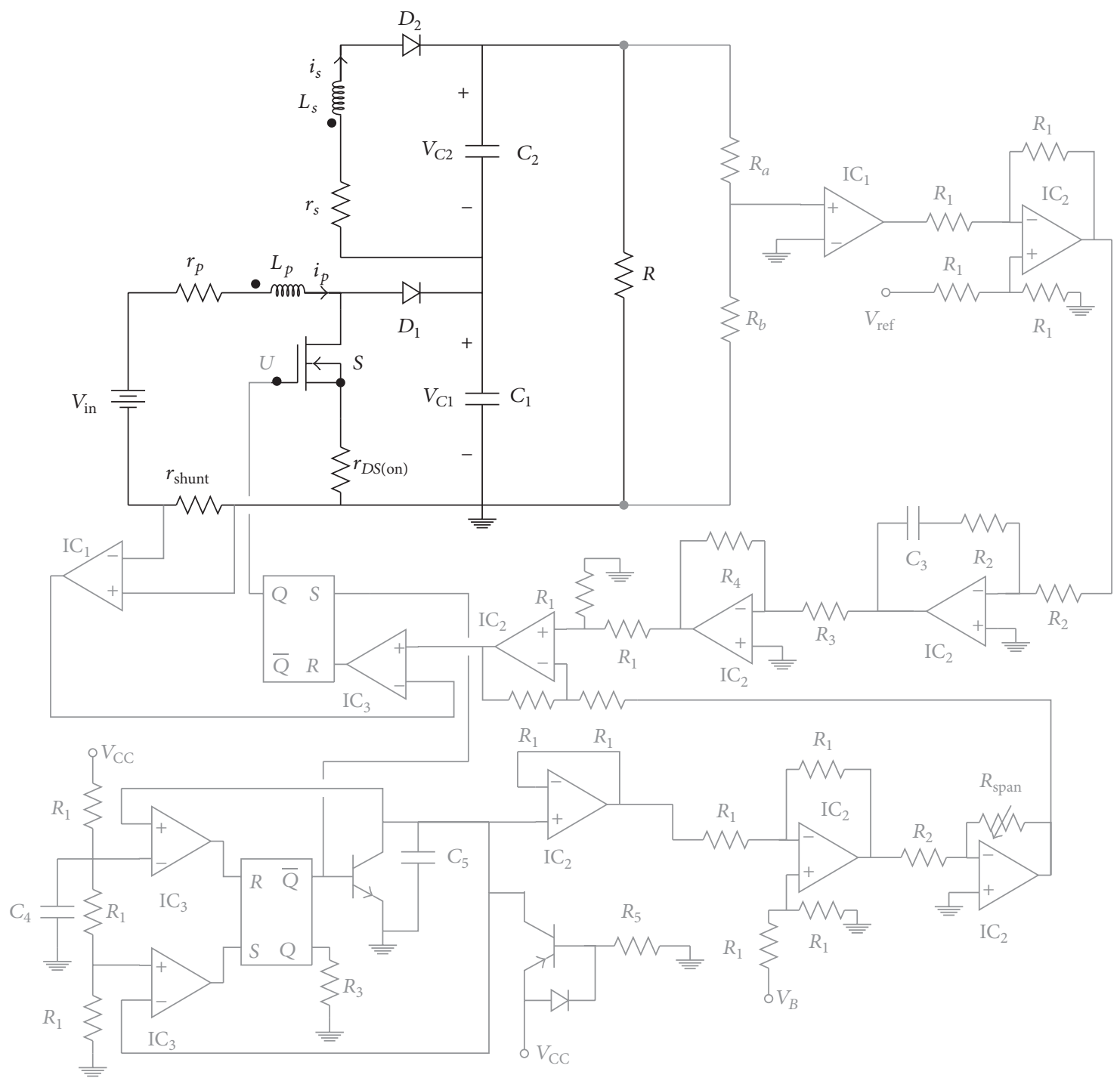

FIGURE 9: Circuit diagram of the experimental set-up.

to $18 \Omega$ depending on the compensation ramp value. For example, for $A_{r}=0.7, R_{\text {span }}=4.5 \mathrm{~K} \Omega$; for $A_{r}=2.8$, $R_{\text {span }}=18 \mathrm{~K} \Omega$.

Figures 10-12 show different responses depending on the compensation ramp. In particular the transition from period1 to period- 2 to period- 4 orbits can be clearly observed as the ramp varies starting from $A_{r}=2.8$ and ending with $A_{r}$ $=0.7$. Figures $10(\mathrm{a}), 11(\mathrm{a})$, and $12(\mathrm{a})$ show the simulation results of the primary inductor current, which have been scaled to facilitate the comparison with the experimental results, in such a way that both vertical axes represent the same quantities. Figures 10(b), 11(b), and 12(b) show the experimental results of the primary inductor current. The real value of the current is five times the value displayed by the oscilloscope. In all cases, the desired output was $V_{\text {out }}=100 \mathrm{~V}$, and the obtained output voltage was very close to this value regardless the periodicity of the orbit.

Note that period-1 orbit (Figure 10) includes states $E_{3}$ where $i_{p}=0 ; E_{6}$ where $i_{p}$ has a high slope; $E_{5}$ where $i_{p}$ continues growing; and $E_{4}$ where $i_{p}$ decreases to zero and the system turns to $E_{3}$ again. Figure 11 includes state $E_{5}$ in one cycle and $E_{5}, E_{4}, E_{3}$, and $E_{1}$ in the second one. Figure 12 involves the following states and sequences. In the first cycle, the system only works in state $E_{5}$; in the second cycle, $E_{5}, E_{4}$, and $E_{3}$ are present; in the third one, states $E_{6}$ and $E_{5}$ are active; and, in the last one, the system commutes among states $E_{5}, E_{4}$, $E_{3}$, and $E_{1}$.

\section{Conclusions}

The analysis performed in this paper shows that the boostflyback power converter with a PI control for the peakcurrent necessarily requires the use of a compensation ramp, because otherwise the period-1 orbit is always unstable for the input voltage, reference voltage, and load resistance typically chosen in applications.

A complete analysis, including stability, overcompensation, and disturbance rejection, was performed for a set 


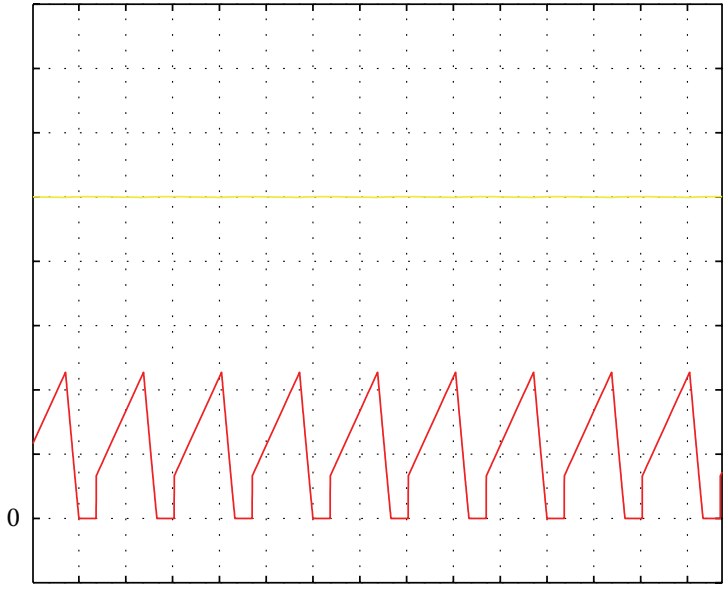

$$
\begin{aligned}
& -i_{p} \rightarrow 500 \mathrm{mV} / \mathrm{Div} \\
& V_{\text {out }} \rightarrow 20 \mathrm{~V} / \mathrm{Div}
\end{aligned}
$$

(a) Simulation results of primary current (red signal) and output voltage (yellow signal)

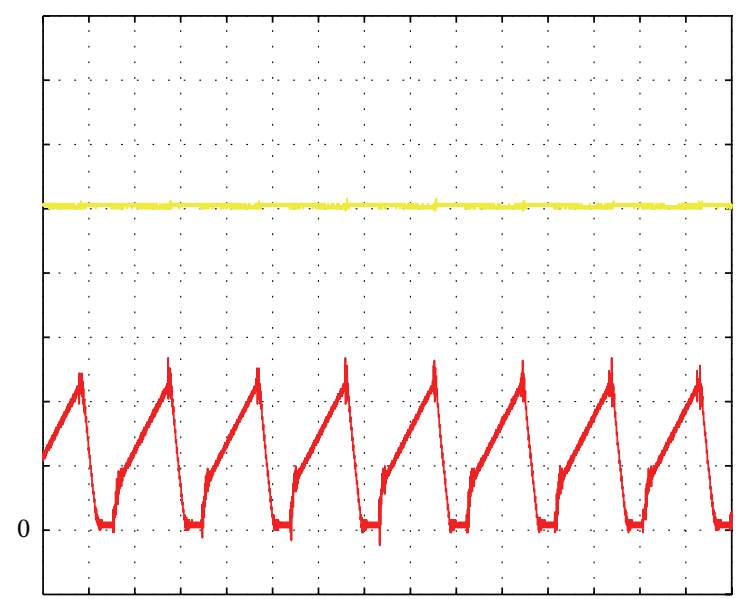

$-i_{p} \rightarrow 500 \mathrm{mV} / \mathrm{Div}$
$-V_{\text {out }} \rightarrow 20 \mathrm{~V} / \mathrm{Div}$

(b) Experimental results of primary current (red signal) and output voltage (yellow signal)

FIgure 10: Period-1 orbit.

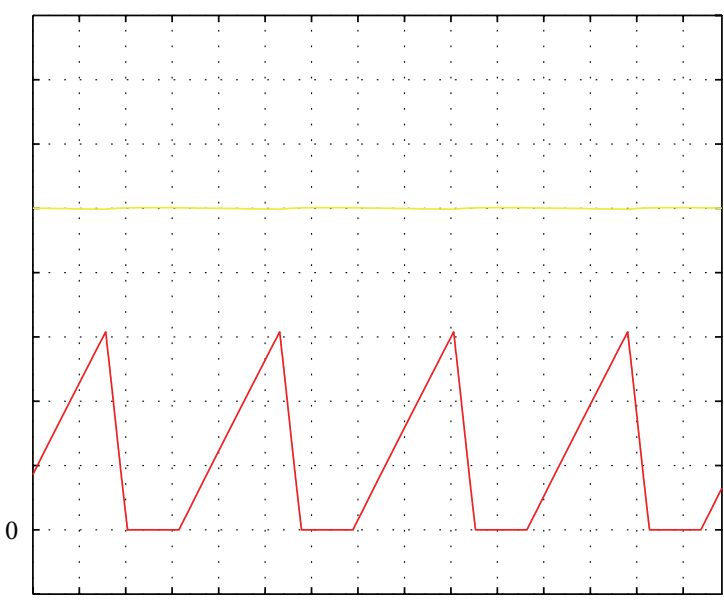

$-i_{p} \rightarrow 500 \mathrm{mV} / \mathrm{Div}$

(a) Simulations of primary current (red signal) and output voltage (yellow signal)

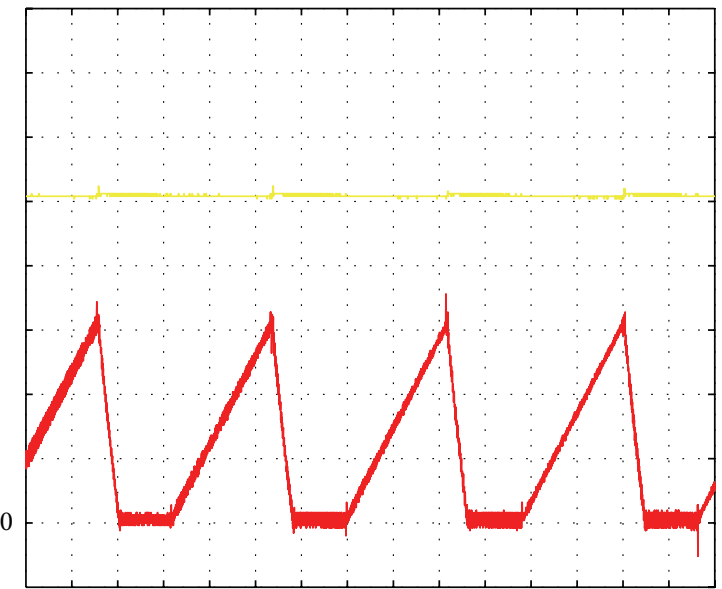

$i_{p} \rightarrow 500 \mathrm{mV} / \mathrm{Div}$
$V_{\text {out }} \rightarrow 20 \mathrm{~V} / \mathrm{Div}$

(b) Experimental results of primary current (red signal) and output voltage (yellow signal)

Figure 11: Period-2 orbit.

of parameter ranges. These analyses let us conclude the value of the compensation ramp and determine the range of the other parameters $V_{\text {in }}, V_{\text {ref }}$, and $R$, such that the power converter works in the same period-1 orbit, despite parameters variations.

Results obtained from the experimental set-up agree with simulations. Particularly, it was possible to see the first period-doubling bifurcation (period-1 to period-2 transition) and the second period-doubling bifurcation (period-2 to period-4 transition). The chaotic behavior was impossible to see due to power constraints of the experiment.
The period-1 orbit given by $E_{6} \rightarrow E_{5} \rightarrow E_{4} \rightarrow E_{3}$ permits amplifying the input voltage up to five times, with duty cycles near to $60 \%$. The duty cycle depends on the load resistance $R$, the input voltage $V_{\text {in }}$, and the reference voltage $V_{\text {ref }}$.

In all cases and ranges analyzed in this paper, the stability is lost by a period-doubling bifurcation. This bifurcation is closely followed by a corner collision, preserving the periodicity of the orbit but changing the states sequence (Figure 11). In this case, the state $E_{6}$ disappears.

Another way to lose the stability of the period-1 orbit is falling into the basin of attraction of the other period- 1 orbit. 


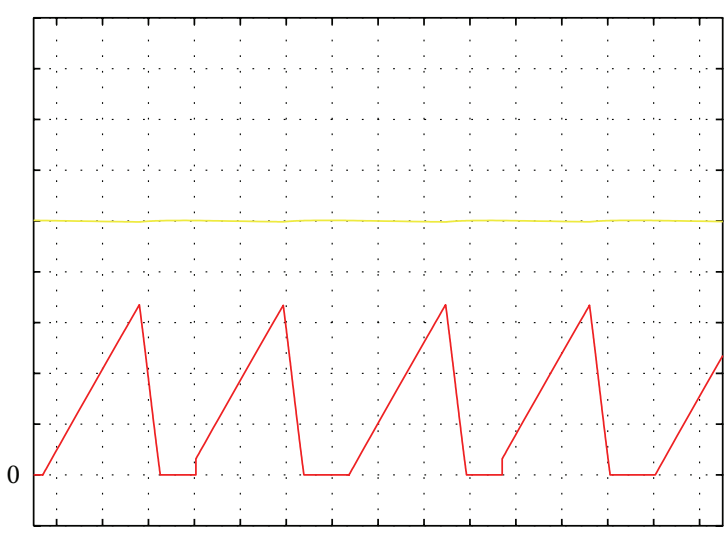

$-i_{p} \rightarrow 500 \mathrm{mV} / \mathrm{Div}$
$V_{\text {out }} \rightarrow 20 \mathrm{~V} / \mathrm{Div}$

(a) Simulations of primary current (red signal) and output voltage (yellow signal)

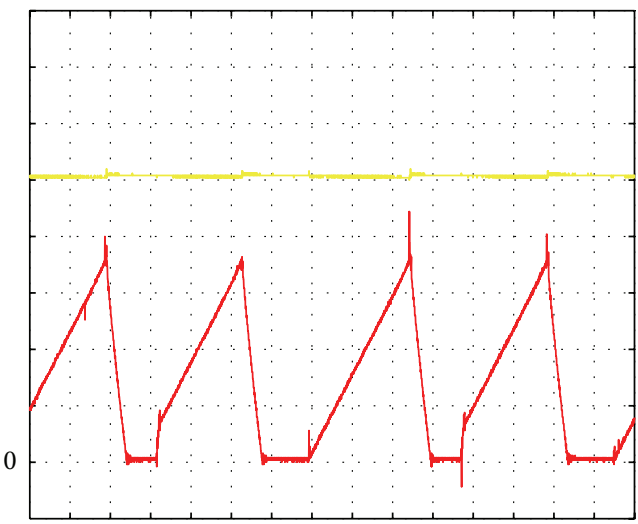

$-i_{p} \rightarrow 500 \mathrm{mV} / \mathrm{Div}$
$V_{\text {out }} \rightarrow 20 \mathrm{~V} / \mathrm{Div}$

(b) Experimental results of primary current (red signal) and output voltage (yellow signal)

Figure 12: Period-4 orbit.

TABLE 3: Performance.

\begin{tabular}{|c|c|c|c|c|}
\hline Analysis & Perturbation & Time (s) & $A_{r}=2.8$ & $A_{r}=10$ \\
\hline$i_{p(\max )}$ & $V_{\text {in }}$ & - & $7.34 \mathrm{~A} / 3.39 \mathrm{~A}$ & $7.404 \mathrm{~A} / 3.386 \mathrm{~A}$ \\
\hline$i_{s(\max )}$ & $R$ & - & $12.36 \mathrm{~A} / 4.4 \mathrm{~A}$ & $12.362 \mathrm{~A} / 4.46 \mathrm{~A}$ \\
\hline \multirow{6}{*}{$\begin{array}{l}\text { Overshoot }(\max ) \\
\frac{V_{\text {out }}(\max )-V_{\text {out }}(\mathrm{ss})}{V_{\text {out }}(\mathrm{ss})} 100 \%\end{array}$} & \multirow{3}{*}{$V_{\text {in }}$} & 0 & $3.71 \%$ & $5.35 \%$ \\
\hline & & 0.0667 & $1.15 \%$ & $1.69 \%$ \\
\hline & & 0.133 & $0.77 \%$ & $1.07 \%$ \\
\hline & \multirow{3}{*}{$R$} & 0 & $3.05 \%$ & $4.53 \%$ \\
\hline & & 0.0667 & $3.13 \%$ & $3.17 \%$ \\
\hline & & 0.133 & $2.97 \%$ & $3.03 \%$ \\
\hline \multirow{6}{*}{ Settling time } & \multirow{3}{*}{$V_{\text {in }}$} & $0 \leq t<0.0667$ & $32.97 \mathrm{~ms}$ & $36.13 \mathrm{~ms}$ \\
\hline & & $0.0667 \leq t<0.133$ & $4.7 \mathrm{~ms}$ & $16.4 \mathrm{~ms}$ \\
\hline & & $0.133 \leq t<0.2$ & $12.3 \mathrm{~ms}$ & $22.3 \mathrm{~ms}$ \\
\hline & \multirow{3}{*}{$R$} & $0 \leq t<0.0667$ & $48.66 \mathrm{~ms}$ & $57.82 \mathrm{~ms}$ \\
\hline & & $0.0667 \leq t<0.133$ & $42.1 \mathrm{~ms}$ & $42.6 \mathrm{~ms}$ \\
\hline & & $0.133 \leq t<0.2$ & $40.9 \mathrm{~ms}$ & $40.1 \mathrm{~ms}$ \\
\hline \multirow{6}{*}{$\begin{array}{l}\text { Steady state \%e } \\
\int_{0}^{\infty} e(t)^{2} d t\end{array}$} & \multirow{3}{*}{$V_{\text {in }}$} & $0 \leq t<0.0667$ & $0.49 \%$ & $0.49 \%$ \\
\hline & & $0.0667 \leq t<0.133$ & $0.41 \%$ & $0.41 \%$ \\
\hline & & $0.133 \leq t<0.2$ & $0.49 \%$ & $0.49 \%$ \\
\hline & \multirow{3}{*}{$R$} & $0 \leq t<0.0667$ & $0.23 \%$ & $0.23 \%$ \\
\hline & & $0.0667 \leq t<0.133$ & $0.293 \%$ & $0.293 \%$ \\
\hline & & $0.133 \leq t<0.2$ & $0.23 \%$ & $0.23 \%$ \\
\hline
\end{tabular}


TABLE 4: Integrated circuit specifications and parameter values of the experiment.

\begin{tabular}{lc}
\hline Name & Reference/value \\
\hline $\mathrm{IC}_{1}$ & INA128 \\
$\mathrm{IC}_{2}$ & $T L 084$ \\
$\mathrm{IC}_{3}$ & $L M 311$ \\
$R_{a}$ & $2 \mathrm{M} \Omega$ \\
$R_{b}$ & $2 \mathrm{~K} \Omega$ \\
$R_{\text {shunt }}$ & $0.011 \Omega$ \\
$R_{1}$ & $100 \mathrm{~K} \Omega$ \\
$R_{2}$ & $56 \mathrm{~K} \Omega$ \\
$R_{3}$ & $10 \mathrm{~K} \Omega$ \\
$R_{4}$ & $200 \mathrm{~K} \Omega$ \\
$R_{5}$ & $2 \mathrm{~K} \Omega$ \\
$C_{3}$ & $100 \mathrm{nF}$ \\
$C_{4}$ & $10 \mathrm{nF}$ \\
$C_{5}$ & $0.1 \mu \mathrm{F}$ \\
$V_{\mathrm{CC}}$ & $5 \mathrm{~V}$ \\
$V_{B}$ & $1 \mathrm{~V}$ \\
\hline
\end{tabular}

This situation occurs, for example, when the load resistance, input voltage, or reference voltage increases.

\section{Competing Interests}

The authors declare that there are no competing interests regarding the publication of this paper.

\section{Acknowledgments}

This work was supported by Universidad Nacional de Colombia, Manizales, Projects nos. 28528 and 22546, Vicerrectoría de Investigación, DIMA, and COLCIENCIAS under Contract no. FP44842-052-2016, and program Doctorados Nacionales 6172-2013.

\section{References}

[1] R. W. Erickson and D. Maksimović, Fundamentals of Power Electronics, Springer, Berlin, Germany, 2001.

[2] Q. Zhao and F. Lee, "High performance coupled-inductor DCDC converters," in Proceedings of the 18th Annual IEEE Applied Power Electronics Conference and Exposition (APEC '03), vol. 1, pp. 109-113, Miami, Fla, USA, February 2003.

[3] Y. M. Lai, S. C. Tan, and S. N. Chan, "Method of alleviating overcompensation problem in zero-voltage-transition pulse-widthmodulation boost converters," Electronics Letters, vol. 44, no. 6, pp. 444-445, 2008.

[4] K. C. Tseng and T. J. Liang, "Novel high-efficiency step-up converter," IEE Proceedings: Electric Power Applications, vol. 151, no. 2, pp. 182-190, 2004.

[5] T. J. Liang and K. C. Tseng, "Analysis of integrated boost-flyback step-up converter," IEE Proceedings-Electric Power Applications, vol. 152, no. 2, pp. 217-225, 2005.

[6] N. A. Carrero Candelas, Modelado, simulación y control de un convertidor boost acoplado magnéticamente [Ph.D. dissertation], Universitat Politècnica de Catalunya, 2014.
[7] L. Wuhua, X. Jianguo, W. Jiande, L. Jun, and X. He, "Application summarization of coupled inductors in DC/DC converters," in Proceedings of the 24th Annual IEEE Applied Power Electronics Conference and Exposition (APEC'09), pp. 1487-1491, Washington, Wash, USA, February 2009.

[8] S.-M. Chen, C.-Y. Wang, and T.-J. Liang, "A novel sinusoidal boost-flyback CCM/DCM DC-DC converter," in Proceedings of the 29th Annual IEEE Applied Power Electronics Conference and Exposition (APEC '14), pp. 3512-3516, Fort Worth, Tex, USA, March 2014.

[9] J. Graw and H. Zimmermann, "Charging multiple batteries using the boost-flyback converter," in Proceedings of the IEEE International Energy Conference and Exhibition (ENERGYCON '12), pp. 963-967, Florence, Italy, September 2012.

[10] H.-Y. Li and H.-C. Chen, "Dynamic modeling and controller design for a single-stage single-switch parallel boost-flybackflyback converter," IEEE Transactions on Power Electronics, vol. 27, no. 2, pp. 816-827, 2012.

[11] Z. Chen, Q. Zhou, and J. Xu, "Coupled-inductor boost integrated flyback converter with high-voltage gain and ripple-free input current," IET Power Electronics, vol. 8, no. 2, pp. 213-220, 2015.

[12] D. Xu, Y. Cai, Z. Chen, and S. Zhong, "A novel two winding coupled-inductor step-up voltage gain boost-flyback converter," in Proceedings of the International Power Electronics and Application Conference and Exposition, pp. 1-5, IEEE, Shanghai, China, November 2014.

[13] T.-J. Liang, S.-M. Chen, L.-S. Yang, J.-F. Chen, and A. Ioinovici, "A single switch boost-flyback DC-DC converter integrated with switched-capacitor cell," in Proceedings of the IEEE 8th International Conference on Power Electronics and ECCE Asia (ICPE \& ECCE '11), pp. 2782-2787, Jeju Island, South Korea, May 2011.

[14] M. Das and V. Agarwal, "Generalized small signal modeling of coupled inductor based high gain, high efficiency dc-dc converters," in Proceedings of the 30th Annual IEEE Applied Power Electronics Conference and Exposition (APEC '15), pp. 2691-2695, Charlotte, NC, USA, March 2015.

[15] S.-M. Chen, T.-J. Liang, L.-S. Yang, and J.-F. Chen, "A cascaded high step-up DC-DC converter with single switch for microsource applications," IEEE Transactions on Power Electronics, vol. 26, no. 4, pp. 1146-1153, 2011.

[16] M. Bernardo, C. Budd, A. Champneys, and P. Kowalczyk, Piecewise-Smooth Dynamical Systems, Theory and Applications, Springer, Berlin, Germany, 2008.

[17] R. I. Leine, D. H. van Campen, and B. L. van de Vrande, "Bifurcations in nonlinear discontinuous systems," Nonlinear Dynamics, vol. 23, no. 2, pp. 105-164, 2000.

[18] D. Giaouris, S. Banerjee, B. Zahawi, and V. Pickert, "Stability analysis of the continuousconduction-mode buck converter via Filippov's method," IEEE Transactions on Circuits and Systems I: Regular Papers, vol. 55, no. 4, pp. 1084-1096, 2008.

[19] T. Grote, F. Schafmeister, H. Figge, N. Fröhleke, P. Ide, and J. Böcker, "Adaptive digital slope compensation for peak current mode control," in Proceedings of the IEEE Energy Conversion Congress and Exposition (ECCE '09), pp. 3523-3529, San Jose, Calif, USA, September 2009.

[20] J. Zhong and S. Liu, "Design of slope compensation circuit in peak-current controlled mode converters," in Proceedings of the International Conference on Electric Information and Control Engineering (ICEICE '11), pp. 1310-1313, Wuhan, China, April 2011. 
[21] J. Morcillo Bastidas, D. Burbano Lombana, and F. Angulo, "Adaptive ramp technique for controlling chaos and sub-harmonic oscillations in DC-DC power converters," IEEE Transactions on Power Electronics, vol. 31, no. 7, pp. 5330-5343, 2016.

[22] F. Florez, J. Munoz, and F. Angulo, "Modeling, simulation and experimental set-up of a boost-flyback converter," in Proceedings of the IEEE 2nd Colombian Conference on Automatic Control (CCAC '15), pp. 1-4, Manizales, Colombia, October 2015.

[23] F. Tian, S. Kasemsan, and I. Batarseh, "An adaptive slope compensation for the single-stage inverter with peak current-mode control," IEEE Transactions on Power Electronics, vol. 26, no. 10, pp. 2857-2862, 2011.

[24] S. Samanta, P. Patra, S. Mukhopadhyay, and A. Patra, "Optimal slope compensation for step load in peak current controlled dcdc buck converter," in Proceedings of the 13th International Power Electronics and Motion Control Conference (EPE-PEMC '08), pp. 485-489, Poznan, Poland, September 2008.

[25] R. Redl and N. O. Sokal, "Current-mode control, five different types, used with the three basic classes of power converters: small-signal ac and large-signal dc characterization, stability requirements, and implementation of practical circuits," in Proceedings of the IEEE Power Electronics Specialists Conference, pp. 771-785, Toulouse, France, June 1985.

[26] R. I. Leine and H. Nijmeijer, Dynamics and Bifurcations of NonSmooth Mechanical Systems, vol. 18, Springer, Berlin, Germany, 2004.

[27] Y. A. Kuznetsov, Elements of Applied Bifurcation Theory, Springer, Berlin, Germany, 2004. 


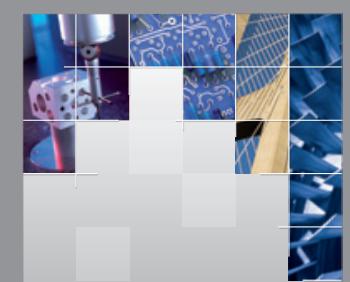

\section{Enfincering}
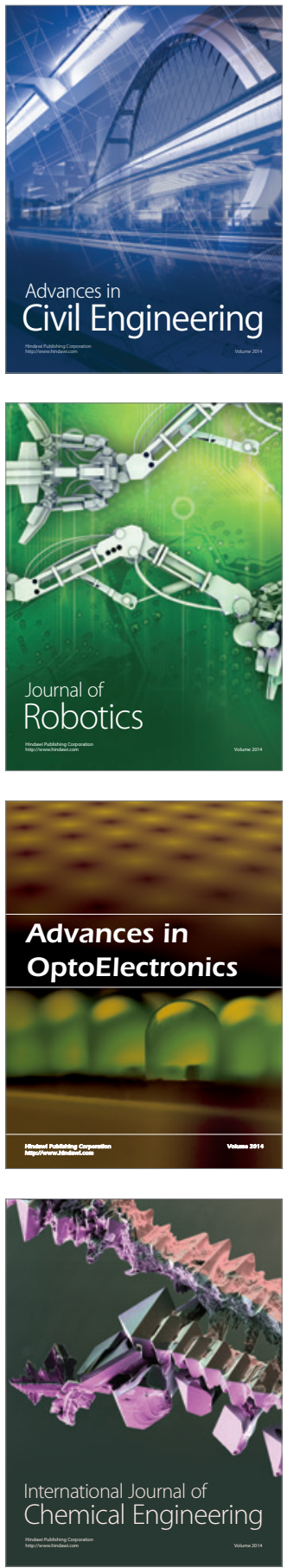

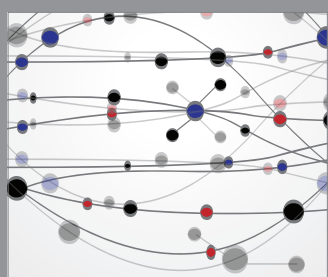

The Scientific World Journal

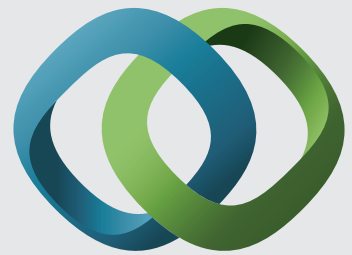

\section{Hindawi}

Submit your manuscripts at

http://www.hindawi.com
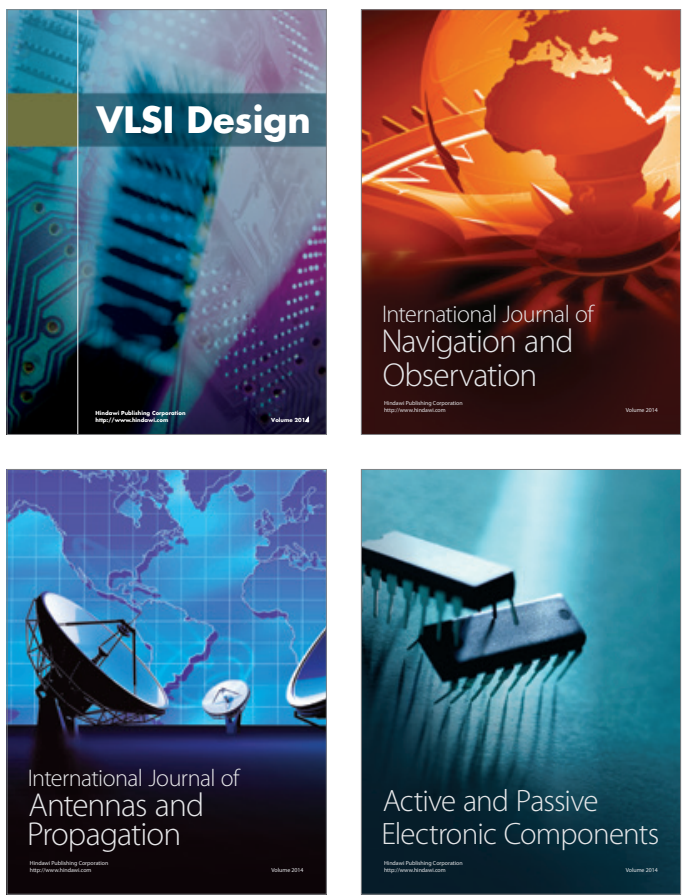
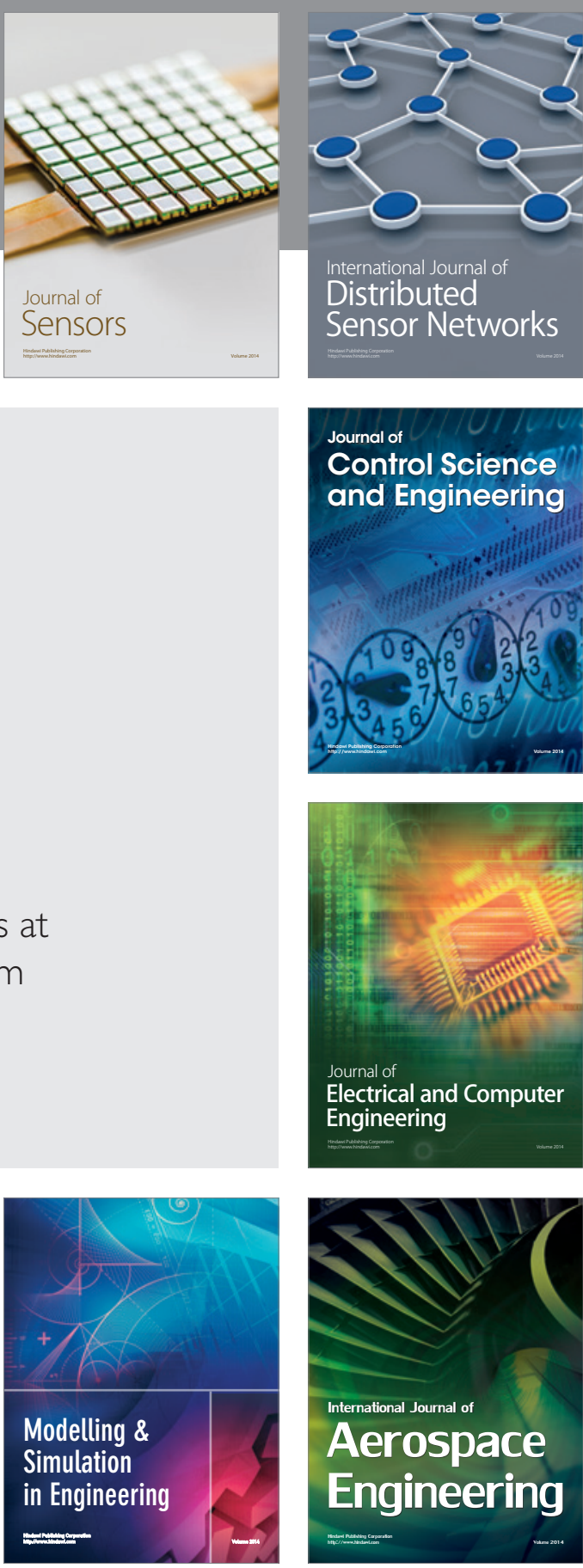

International Journal of

Distributed

Sensor Networks

Journal of

Control Science

and Engineering
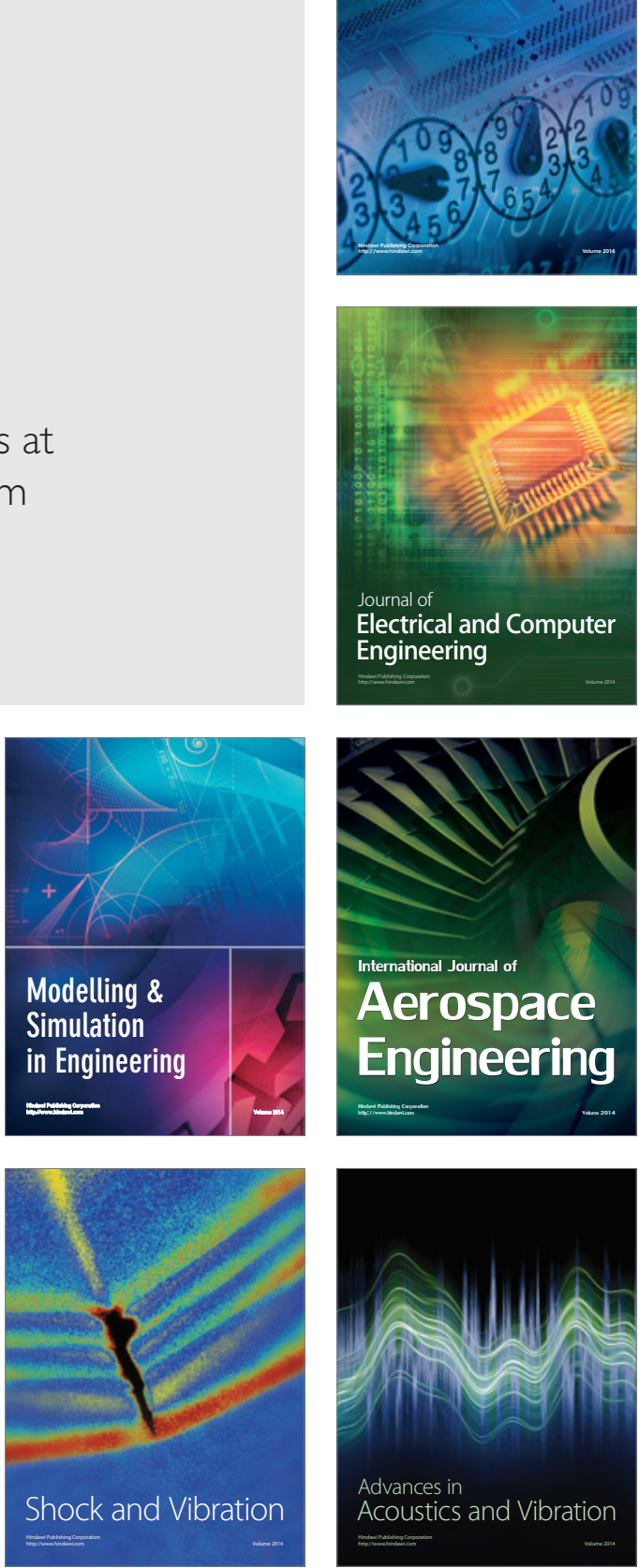